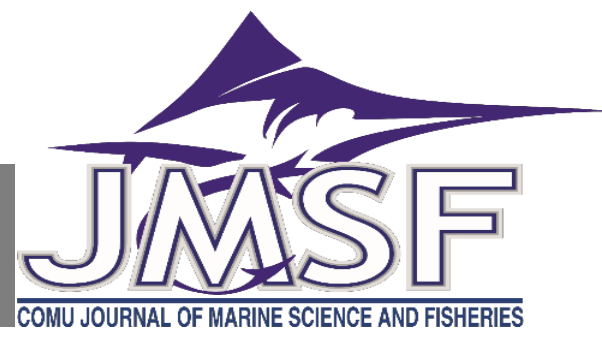

RESEARCH ARTICLE

\title{
Analysis of the Fourth Generation Buy-Back Program for Fishing Vessels in Turkey
}

\author{
Vahdet Ünal, Huriye Göncüoğlu-Bodur* \\ Ege Üniversitesi Su Ürünleri Fakültesi, Bornova, Izmir, Türkiye \\ Correspondent: huriyegoncuoglu@gmail.com \\ Received: 19.05.2020 Accepted: 16.06.2020 \\ Vahdet Ünal: Orcid 0000-0001-6157-0590, Huriye Göncüoğlu-Bodur: Orcid 0000-0001-7068-037X
}

How to cite this article: Ünal, V., \& Güncüoğlu-Bodur, H., (2020). Analysis of the Fourth Generation Buy-Back Program for fishing vessels in Turkey. COMU J. Mar. Sci. Fish, 3(1): 38-44. DOI: 10.46384/jmsf.739631

\begin{abstract}
In this study, the results of the fourth buy-back program in Turkey which entered into force by the "Notice of Agricultural Support-Official Notice of Decommissioning of Fishing Vessels", issued by the Directorate of Fishery and Aquaculture of the Ministry of Agriculture and Forestry, was evaluated. In the program, a total of 213 fishing vessels were taken back for a total of 22.4 million Turkish Lira. In this study, simple random sampling method was used to interview $24.4 \%$ of the fishing vessels owners. The highest number of buy-backs was in Marmara Region (39\%), followed by the Aegean (12\%) Region. A total of 213 fishing vessels ranging 10,00 m-12,00 m meters in length applied for the buy-back program which were all decommissioned. All of the buy-back vessels were in the small-scale category. Among those, $30 \%$ of the vessels were in use for less than 120 days/year and 46\% were fishing between 120-239 days/year. Among those, $24 \%$ of the vessels were in use for more than 240 days/year. However, $13 \%$ of the owners who handed over their vessels also owned a second boat. Seventy eight percent of the fishers who participated in the program stated that they would remain in fishing even if they gave their vessels, and further indicated that they would buy a new vessel with the support they received from the program. $96 \%$ of the fishers employed a crew on-board and $51 \%$ of their crew were not family members. In addition, $46 \%$ of the crew announced that they would continue to work in the field of fishery. In conclusion; the fourth generation buyback program had ambitious objectives such as reducing fishing effort, increasing efficiency in fishing, reducing pressure on fish stocks and supporting sustainable fishing. Current findings indicate that it is not possible to produce long-term positive effects. Therefore, all details of the results and the success of the buy-back programs should be evaluated by the authorities and future programs should be put into practice with necessary amendments.
\end{abstract}

Keywords: Fisheries Buy-Backs, Vessel Decommissioning, Reducing Fishing Effort, Reducing Fleet Capacity, Fisheries Management

\section{Türkiye’de Dördüncü Balıkçı Gemisi Geri-Alım Programının Analizi}

Özet: Bu çalışma, Tarım ve Orman Bakanlığı Balıkçılık ve Su Ürünleri Genel Müdürlüğü tarafından çıkarılan bir tebliğ ile uygulamaya geçirilen dördüncü balıkçı gemisi geri-alım programını değerlendirmektedir. Programda 22,4 milyon Turkish Lira karşılığında, toplam 213 balıkçı gemisi geri alınmıştır. Çalışmanın verileri, oransal örnek hacmi dikkate alınarak gemi sahiplerinin \%24,4'üyle yapılan görüşmelerden elde edilmiştir. En fazla gemi alımı; Marmara (\%39), en az gemi alımı da Ege bölgesinden (\%12) yapılmıştır. Programa, 10,00 m-12,00 m arası 213 balıkçı gemisi başvurmuş ve bunların geri-alımı gerçekleşmiştir. Devredilen gemilerin tamamı küçük ölçekli balıkçı gemisi kategorisinde yer almaktadır. Bu gemilerin \%30'u, yılda 120 günden az, \%46's1 ise 120-239 gün arası avcılık yapmaktadır Yılda 240 günden fazla avcılık yaptığını bildiren balıkçıların oranı \%24'tür. Balıkçı gemilerini devreden kişilerin \%13'ü ikinci bir gemiye sahiptir. Programa katılan fakat gemisini verse de balıkçılıkta kalmaya devam edeceğini bildiren balıkçıların \%78'si, geri-alım programından aldıkları destekleme ile yeni bir balıkçı gemisi alacağını bildirmiştir. Balıkçı gemilerinin \%96'sı sezonluk veya sürekli mürettebat çalıştırmaktadır. Bu tayfaların \%51'nin aile dışındaki kişilerden oluştuğu tespit edilmiştir. Bunlara ilave olarak, mürettebatın \%46'sı balıkçılık sektöründe çalışmaya devam edeceğini açıklamıştır. Sonuç olarak, incelenen balıkçı gemisi geri-alım programının, balıkçı filosundan sayıca azaltma yapmak suretiyle; balıkçılıkta etkinliği arttırmak balık stokları üzerindeki baskıyı azaltmak ve sürdürülebilir balıkçılığı desteklemek gibi iddialı amaçları olduğu görülmektedir. Çalışmanın mevcut bulguları, programın amaçları doğrultusunda uzun dönemli olumlu etkiler ortaya çıkarmasının mümkün olmadığını göstermektedir. Bu nedenle, geri alım programlarının sonuç ve başarılarının detayları ile ilgili tüm değerlendirmeler otoriteler tarafından yapılmalı ve gelecekteki programlar gerekli düzeltmeler eşliğinde gerçekleştirilmelidir.

Anahtar Kelimeler: Balıkçılık Geri-Alımları, Balıkçı Gemisi Hizmetten Alma, Avcılık Kapasitesinin Azaltılması, Filo Kapasitesinin Azaltılması, Balıkçılık Yönetimi. 


\section{Giriş}

Başarılı balıkçılık yönetimi üzerine yazılanlar, balıkçılığın çökmesi ve bunun nedenlerini ortaya koyanların aksine çok daha azdır (Bartley, 2019). Balık stoklarının değişen, çoğu zaman tam olarak bilinmez, hareketli ve karmaşık yapısı dikkate alındığında, av-avcı dengesini (balık stokları-av kapasitesi), sürdürülebilirlik doğrultusunda tesis etmek, çoğu zaman başarısızlıkla sonuçlanmıştır. Kıyısal ülkeler, bir yandan bu dengeyi sağlamaya bir yandan da balıç̧ılık yönetiminin çevresel, biyolojik ve sosyo-ekonomik boyutunu dikkate alarak sektörün ve kaynakların sürdürülebilir yönetimini gerçekleştirmeye çalışmaktadır.

Geleneksel balıç̧ılık yönetimi tedbirlerinin, farklı yönetim yaklaşımlarının yegane amacı, balıkçılığın sürdürülebilirliğini garanti altına almaktır. Balıkçı gemisi ruhsatlarının dondurulması, bazı alanların balıkçılığa kapatılması, sezon yasakları ve ağ göz açıklığı sınırlandırmaları gibi birçok yönetim uygulamasına rağmen balık stokları aşıra avcılığa maruz kalmaktadır. Öte yandan balıkçılığın karlı olmaktan çıktığı, birçok balıkçı filosunun ekonomik performansının kötüye gittiği görülmektedir. Örneğin, Avrupa Birliği balıkçı filosu ekonomik performansı yıllardır dalgalanmalar göstermektedir (STECF, 2015; STECF, 2016; STECF, 2017; STECF, 2018; STECF, 2019). STECF (2016), büyük ölçekli balıkçı filosu için ekonomik performans iyileşirken küçük ölçekli kıyı filolarının ekonomik performansının kötüleştiğini rapor etmektedir. STECF (2019), Avrupa Birliği büyük ölçekli balıkçı fillosunun 2017 yılında iyiye gittiğini rapor etse de küçük ölçekli balıkçılık için durum biraz daha karmaşık bir tablo sergilemektedir. 2017'de AB üye ülkeleri küçük ölçekli balıkçılık filoları bir bütün olarak kârlı görünmesine rağmen, detaylı sonuçlar, beş küçük ölçekli balıkçı fillosunun brüt kayıp ve dokuzunun da net zarar verdiğini ortaya koymaktadır (STECF, 2019). Günümüzde birçok ülke, aşırı balıkçılık kapasitesi ve bunun doğal sonucu olarak ortaya çıkan aşırı avcılık problemiyle başa çıkmaya çalışmaktadır. $\mathrm{Bu}$ anlamda farklı politikalar ve yönetim araçları uygulamaya geçirilir. $\mathrm{Bu}$ araçlardan biri de; balıkçılıkta geri-alım programlarıdır.

Balıkçılık kapasitesini azaltmak için tercih edilen programların; balıkçılıkta karlılığın sağlanması, balık stoklarının korunması, filoların modernizasyonu ve yeniden yapılandırılması, ekosistemin korunması gibi birçok hedefi olabileceği, daha önceki çalışmalarda detaylı bir şekilde belirtilmiştir (Holland ve diğ., 1999; Groves ve Squires, 2007; Ekmekci ve Ünal, 2019). Balıkçılıkta geri-alım programları Kanada'dan Güney Doğu Asya'ya, Avrupa Birliği (AB)'nden Avustralya'ya kadar geniş bir coğrafyada, yaklaşık yarım asırdır tercih edilen ancak etkisi tartışılmaya devam eden programlardır (Curtis ve Squires, 2007).

Geri-alım programlarıyla filodaki gemi sayısını azaltan fakat balık stokları üzerindeki baskıyı düşürmeyi başaramayan birçok uygulama örneği vardır. Bu örneklere rağmen, balıkçı gemisi gerialım programlarına olan ilginin devam etmesi ilginç bulunabilir. Üstelik bu türden yönetim araçlarını tercih etmenin yüksek maliyetleri vardır.

Teh ve diğ., (2017) Avustralya, Amerika Birleşik Devletleri, Kanada ve Norveç’te balıkçılık geri-alım programlarını incelemiştir. Yazarlar, her bir geri-alımın sonucunu, yönetimin ekonomik, ekolojik ve sosyal hedefleri ne ölçüde gerçekleştirdiğine göre değerlendirmiştir. Sonuçlar, geri-alımların en azından kısa vadede balıkçılık kapasitesinin azaltılması ve ekonomik karların artırılması gibi belirli program hedeflerine ulaşmada başarılı olabileceğini göstermektedir. Bununla birlikte, değerlendirilen geri-alımların hiçbiri, gizli lisansların varlığı, çaba sarfiyatı ve devam eden balıkçılık yatırımları nedeniyle büyük bir başarı değildi.

Grafton (2008), Kanada Okyanus ve Balıkçılık Dairesi'nin öncelikle gemi geri alımları ve balıkçılık ruhsatları yoluyla somon endüstrisindeki kronik aşırı kapasiteyi ele almaya çalıştığını bildirmiştir. 1970 ve 2000 yılları arasında beş büyük geri alım gerçekleşmiştir; bunların en önemlisi, gemi sayısını yarıya indiren 1998-2000 geri alımı olarak dikkat çekmektedir. Son otuz yılda yaklaşık 300 milyon dolarlık gerçek harcamalara rağmen, geri alımlar uzun vadeli faydalar sağlayamamıştır.

Balıkçılıkta geri-alım programlarının, daha dar kapsamıla balıç̧ı gemilerini hizmetten çıkarma programlarının sadece belirli durumlarda yararlı bir politika aracı olduğu görülmektedir. Dünyanın çeşitli bölgelerinde durum böyleyken, Türkiye 2012 yılında çıkarılan tebliğ (Tebliğ No: 2012/51) ile balıkçı gemisi geri-alım programlarının ilkini uygulamaya geçirerek filo küçültülmesi ve balıkçılık gücünün azaltılmasına yönelik bir girişimde bulunmuştur (GTHB, 2012; Ünal ve diğ., 2015; Göktay ve diğ., 2018; Ekmekci ve Ünal, 2019). Curtis ve Squires (2007), balıkçılık geri-alım programları hakkında, birçok ülkeyi kapsayan ayrıntılı bilgiler vermektedir. Türkiye'de uygulanan ilk üç geri-alım programı hakkında sınırlı sayıda çalışma yapılmıştır. Bu çalışmalar (Ünal ve diğg., 2015; Göktay ve diğ., 2018; Ekmekci ve Ünal, 2019; Ünal ve Göncüoğlu-Bodur, 2020), geri-alım programlarına hangi balıkçıların neden ilgi gösterdiği, bu balıkçıların sosyo-demografik ve ekonomik özellikleri, programdan memnun olup olmadıkları, filodan çıkarılacak gemilerin özellikleri gibi konulara açıklık getirmektedir. 
Balıkçılık geri-alımlarının asıl amacı, aşırı balıkçılık kapasitesini ve balık kaynaklarının aşırı sömürülmesini ele almak olsa da (Squires 2010), geri-alım programlarının balıkçılık kapasitesi ve balık kaynaklarının yanı sıra, balıkçılıktan ayrılan balıkçılar ve balıkçılıkta kalmayı tercih edenler üzerinde sosyo-ekonomik bir etkisi vardır.

Bu çalışma, 3 Ekim 2016 tarihinde çıkarılan Balıkçı Gemisini Avcılıktan Çıkaranlara Yapılacak Destekleme Tebliği (Tebliğ No: 2016/40, say1: 29846) ile başlatılan dördüncü geri- alım programını ele almaktadır. Çalışma, kendisinden önceki programların ele aldığı konulara (teknesini programa veren balıkçıların sosyo-demografik özellikleri, programa verilen teknelerin özellikleri, programdan duyulan memnuniyet, tayfaların dikkate alınıp alınmadığı vb) açıklık getirmek suretiyle, Türkiye'deki geri-alım programlarının sonuçlarıyla ilgili bilginin büyütülmesine ve ilgili politikaların üretilmesine katkı vermeyi hedeflemektedir.

\section{Materyal ve Yöntem}

Çalışmada, ana kitleyi en iyi düzeyde temsil edecek örnek sayısının belirlenmesinde oransal yaklaşım yönteminden yararlanılmıştır (Newbold, 1995). Örnek hacmi belirlenmesinde, $\% 90$ güven aralığında ve \%10 hata payı dikkate alınarak hesaplama yapılmıştır. Hesaplama sonucu, 213 gemi sahibi balıkçı arasından oransal örneklem hacmi hesaplaması sonucu 52 gemi sahibi balıkçı belirlenmiştir. Örneğe giren 52 balıkçı gemisinin ana kitleden belirlenmesinde ise basit tesadüfi örneklem (De Vaus, 1990) seçimi kullanılmıştır. Belirlenen balıkçılarla telefon anketi yapılmıştır. Programın incelenmesi amaciyla, geri-alım programından faydalanan balıkçılara 2018 yılında anket çalışması uygulanmıştır. Anket verilerinin değerlendirilmesinde betimsel analizler, frekans dağılımları, basit ortalamalar, oransal dağılımlar kullanılmıştır.

\section{Bulgular}

Ankete katılan balıkçı gemisi sahiplerinin demografik özellikleri; yaş ortalaması $46,7 \pm 11,7$ (min.24-maks.78) y1l ve eğitim seviyesi ortalama 7,9 $\pm 3,8$ (min.5-maks.15) yıldır. Balıkçı gemisi sahiplerinin \%89'u evli ve \%72'si ev sahibidir. Herhangi bir sosyal güvenceye sahip olmayan balıkçıların oranı sadece \%10'dur. Balıkçıların \%55'i ilkokul mezunudur. Balıkçıların bakmakla yükümlü oldukları kişi sayısı 3,3 $\pm 1,6$ 'dır. Balıkçıların ortalama balıkçılık tecrübesi 19,8 $\pm 12,4$ yıldır (şekil 1). Balıkçıların \%58'nin geçinmeleri için balıkçılığa ihtiyaç duymadığı, geçimleri için balıkçılık haricinde başka gelirlerinin de olduğu tespit edilmiştir.

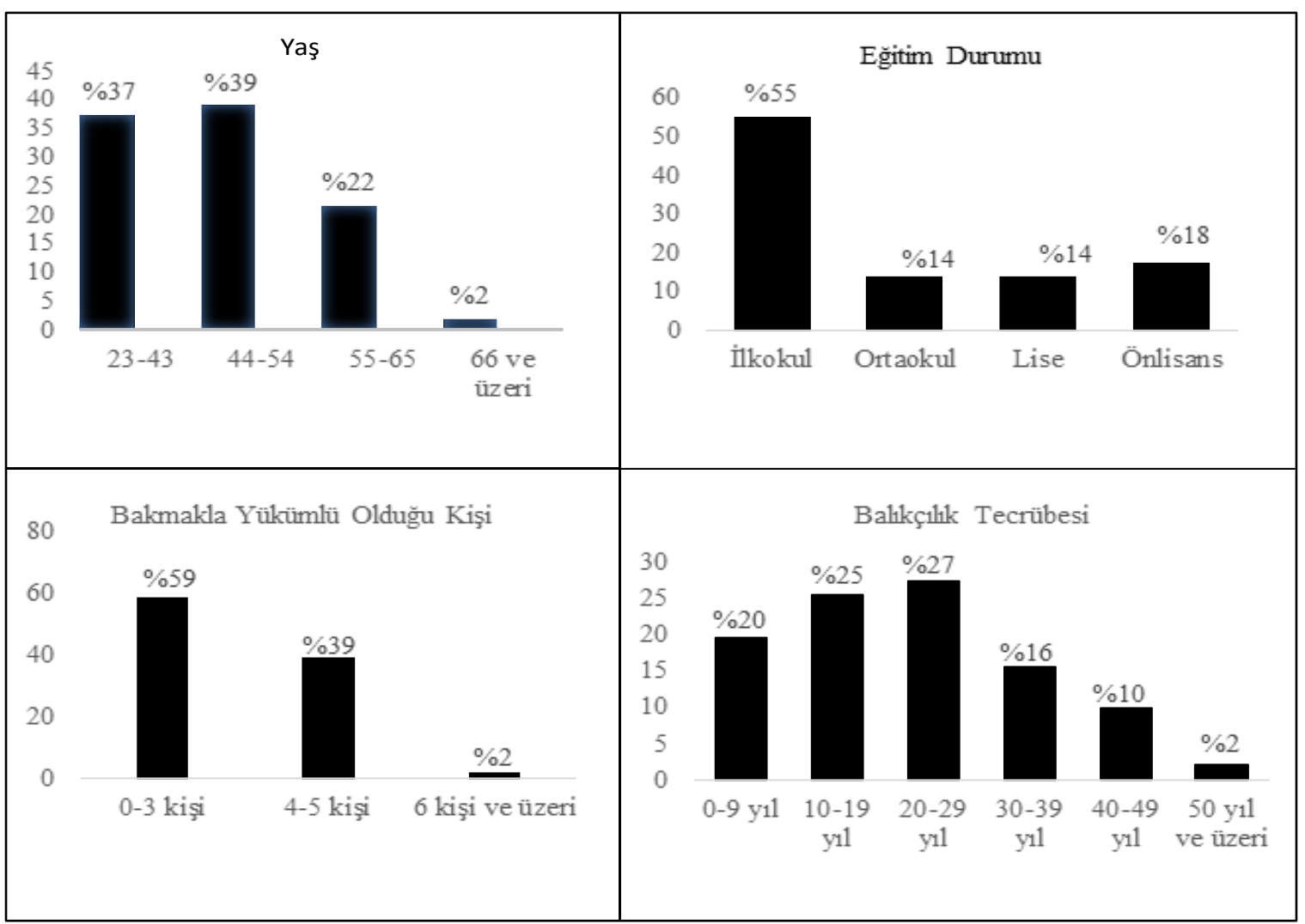

Şekil 1. Geri-alım programına katılan balıkçıların demografik özelliklerinin oransal dağılımı 


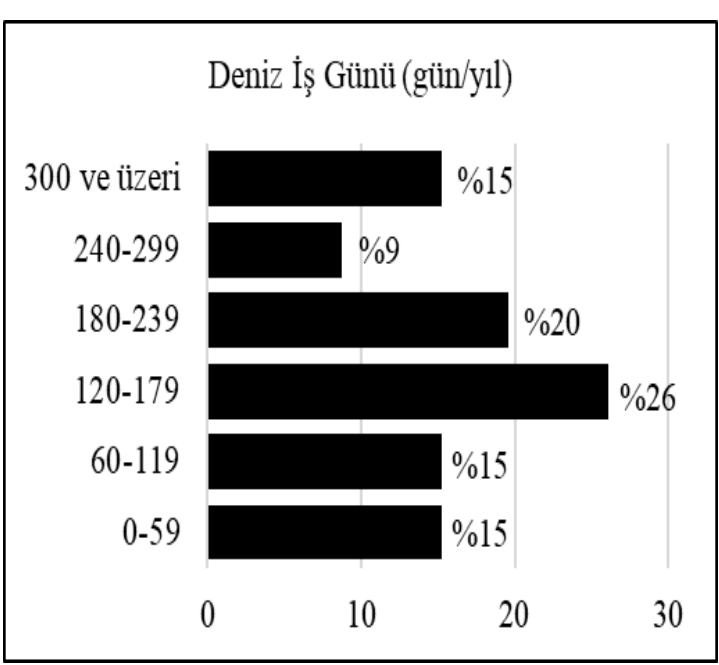

Şekil 2. Geri-alımı gerçekleşen gemilerin deniz iş günlerinin oransal dağılımı

Geri-alımı gerçekleşen balıkçı gemilerinin denizde çalışma süreleri ortalama $162 \pm 94,9$ gün/yıl ve en aktif gemi için ise 310 gün/yıl olarak tespit edilmiştir. Gemilerin \%26's1 120-179 gün/yıl, \%20'si 180-239 gün/yıl denizde çalışmıştır. Sadece \%9'u bir yıl içinde 240-299 günden az süre denizde çalışmıştır. Geriye kalan gemiler \%15'şer oranda (60-119 gün/y1l, 0-59 gün/yıl ve 300 ve üstü gün/yıl) denizde çalışmıştır (Şekil 2).
Programa 10m-12m arasındaki 213 gemi başvuru yapmıştır. En fazla gemi alımı; Marmara (\%39), en az gemi alımı da Ege bölgesinden (\%12) yapılmıştır. 213 gemi arasında sadece 1 tekne $12 \mathrm{~m}$ 'dir. Örneklem hacmine giren gemi boyları ortalama $10,5 \pm 0,5 \mathrm{~m} \quad$ (min.10-max.12m)'dir. Gemilerin \%85'i 10,00m-10,99m arasındadır (Şekil $3)$.

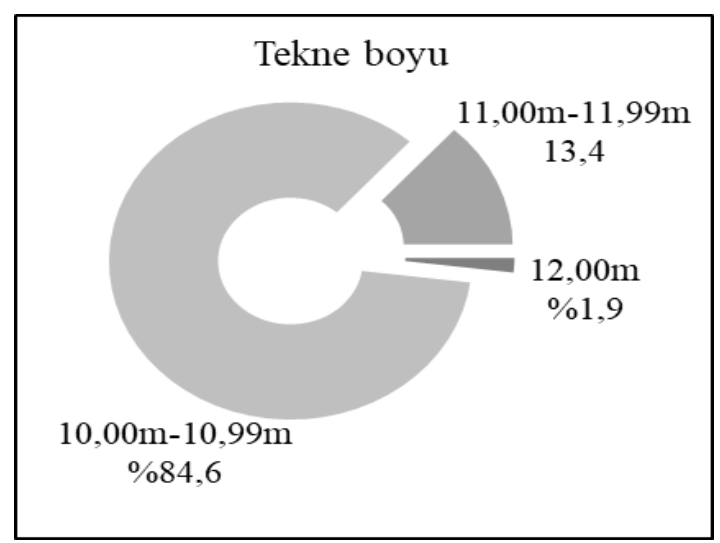

Şekil 3. Geri-alımı gerçekleşen gemilerin tekne boylarının oransal dağılımı

Gemi yaşı ortalama $22,7 \pm 11,2$ yıl iken, ana makine yaşı ortalama 29,3 $\pm 23,3$ yıldır (min. 1 yılmaks. 75 yıl). Ana makina gücü ortalama $81,8 \pm 45,2$ BG (min.15 BG-maks. 220 BG)'dir. Balıçcıların \%65'i sadece uzatma ağı kullanmaktadır (Şekil 4)

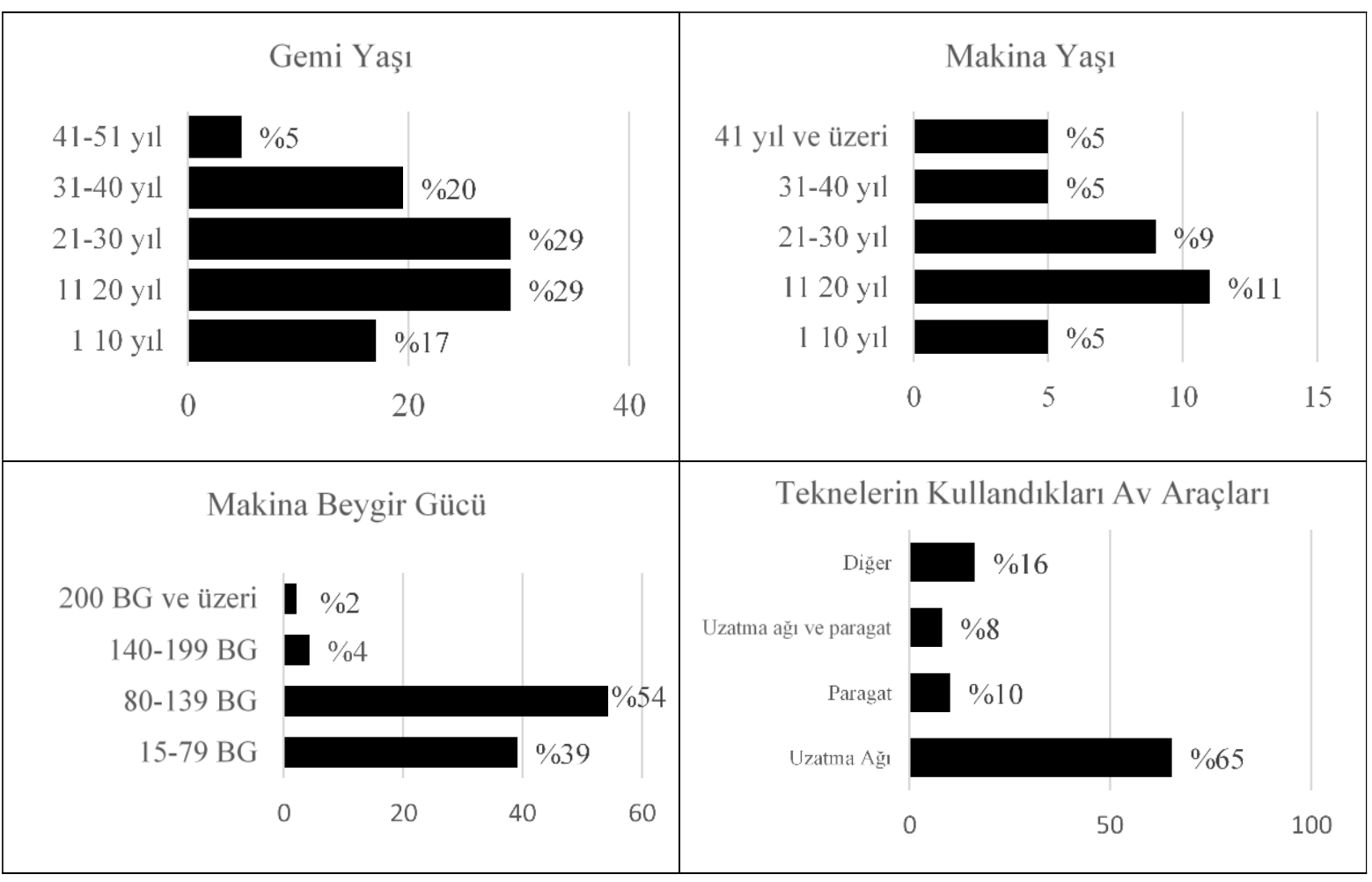

Şekil 4. Geri-alımı gerçekleşen gemilerin yaşı, makina gücü ve kullandıkları av araçlarının oransal dağılımı 
Mürettebatin Balıkçıllğ̆a Devam Etme Kararı

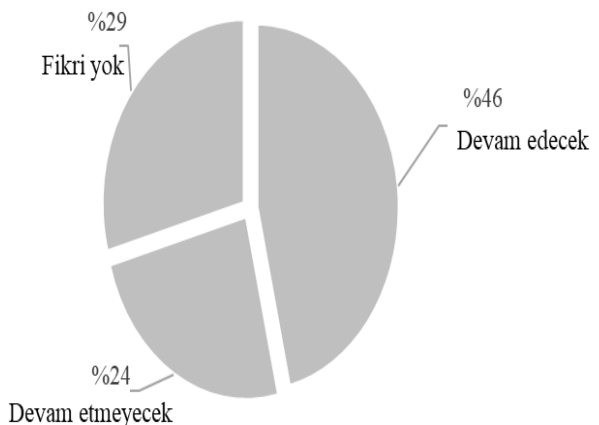

Devam etmeyecek

Şekil 5. Geri-alımı gerçekleşen gemilerde çalışan mürettebatın oransal dağılımı

Balıkçı gemilerinin \%96'sı sezonluk veya sürekli mürettebat çalıştırmaktadır. Çalışan personelin \%49'u aileden ve \%51'i dişarıdan temin edilen tayfalardan oluşmaktadır. Mürettebatın \%46'sı balıkçılığa devam edeceğini, \%29'u henüz ne yapacağına karar vermediğini ve \%24'ü ise balıkçılığa devam etmeyeceğini ifade etmiştir (şekil 5). Bu \%46'lik personelin \%56's1 tayfa olarak ve $\% 44$ ü kendine gemi alarak balıkçılığa devam edeceğini bildirmiştir.
Geri-alım programından faydalanmaya hak kazanan balıkçı gemisi sahiplerinin, geri-alım programına katılmalarına etki eden faktörler, üç etken üzerinde yoğunlaşmıştır. Bu etkenler; a) 'Mevcut geminin değiştirilmek istenmesi' $(\% 23,2)$, b) 'Programın cazip bir firsat olarak görülmesi" $(\% 23,2)$ ve c) "Borçların kapatılmak istenmesi" $(\% 22,2)$ 'dir.

Diğer cevaplar sıklık oranlarına göre aşağıda verilmiştir:

- $\quad \% 13,1$ 'i 'Birden fazla balıkçı gemisine sahip olması"

- $\quad \% 13,1$ 'i 'Balıkçılığın karsız hale gelmesi,

- \%3’ü ise 'Emekli olunarak balıkçılıktan ayrilmak istenmesi'

Programdan faydalanan balıkçıların, \%82'si programı faydalı bulduklarını, \%80'ni programın devam etmesinden memnun olduklarını ve \%74'ü ise geri-alım programında teknelerine biçilen fiyattan memnun olduklarını ifade etmişlerdir (Tablo 1).

Tablo 1. Programdan yararlanan balıkçıların programdan duyulan memnuniyetin oransal dağılımı

\begin{tabular}{lccc}
\hline Memnuniyet Değişkenleri & $\begin{array}{c}\text { Memnun } \\
(\%)\end{array}$ & $\begin{array}{c}\text { Kısmen memnun } \\
(\%)\end{array}$ & $\begin{array}{c}\text { Memnun değil } \\
(\%)\end{array}$ \\
\hline Tekneye biçilen değerden & 74 & 10 & 16 \\
Geri-alım programını faydalı bulma & 82 & 16 & 2 \\
Geri-alım programının devam etmesinden & 80 & 16 & 4 \\
\hline
\end{tabular}
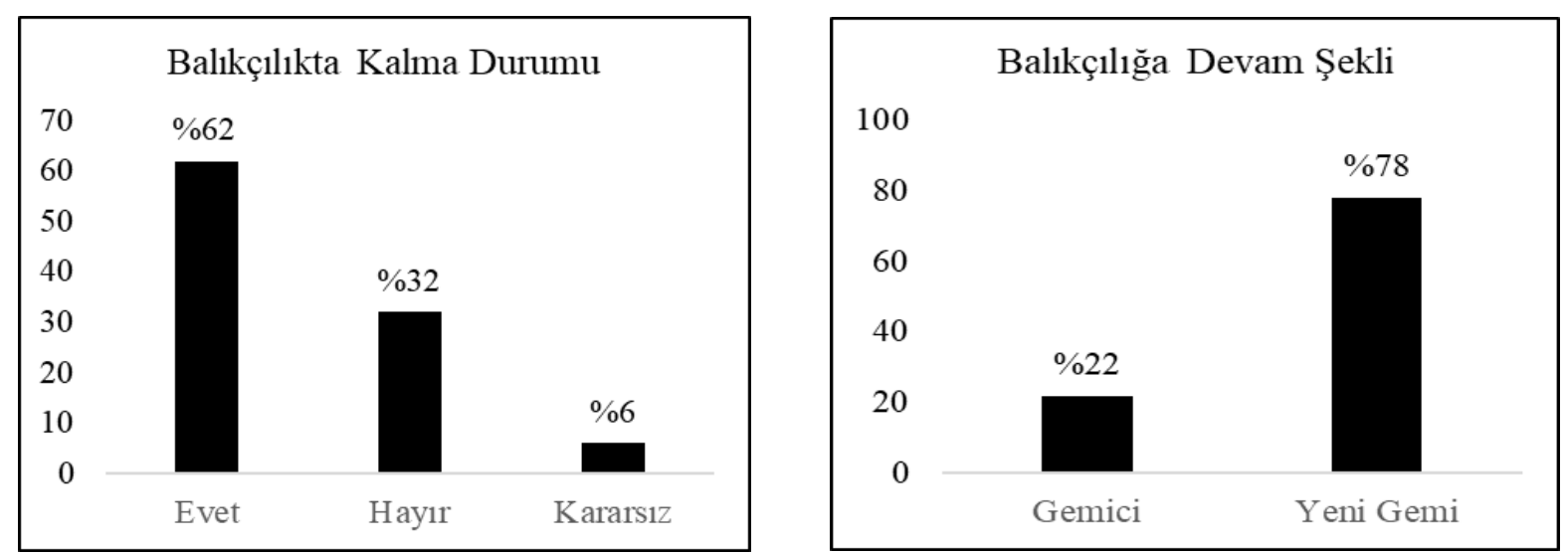

Şekil 6. Gemisini devreden gemi sahiplerinin balıkçılıkta kalma ve devam şekillerinin oransal dağılımı. 
Balıkçı gemisini geri-alım programı kapsamında devreden gemi sahiplerinin \%62'si balıkçılıkta kalmaya devam edeceğini bildirmiştir. Balıkçılıkta kalmaya devam edecek olan balıkçıların, \%78'si ise balıkçılığa eldeki ikinci gemi veya yeni satın alacakları bir gemi ile devam etmeyi düşünmektedir (şekil 6).

\section{Tartışma}

Türkiye balıkçılığında uygulanan dördüncü gerialım programının, kendisinden önceki geri-alım programlarıyla benzerlik gösterdiği söylenebilir. İlk iki balıkçı gemisi geri-alım programında, daha ziyade atıl gemilerin filodan çıkarıldığı (Göktay ve diğ., 2018; Ekmekci ve Ünal, 2019), üçüncü geri-alım programında ise gemi boylarına göre yapılan ödemeleri arttırmak suretiyle, büyük gemilerin filodan çıkarılmasına yönelik strateji izlendiği fakat bu stratejinin karşılık bulamadığı görülmektedir (Ünal ve Göncüoğlu-Bodur, 2020). Bu çalışmada incelenen dördüncü programda ise filodan çekilen gemilerin tamamının küçük ölçekli balıkçı gemisi sıfatı taşıyan gemiler olduğu görülmektedir. Ekmekçi ve diğ., (2019) ikinci programa başvuruların \%80'inin 10-12 m boy aralığında gerçekleştiğini, Ünal ve Göncüoğlu-Bodur (2020) ise devredilen gemilerin \%95'inin küçük ölçekli balıkçı gemisi kategorisinde yer aldığını rapor etmektedir. Mevcut çalışma ise, dördüncü programda alınan tüm gemilerin 10-12 m aralığında yer aldığını ortaya koymaktadır. Sonuç olarak, şu ana kadar uygulanan geri-alım programlarının filoyu sayıca azaltmada başarılı olduğu ancak filo kapasitesini hedeflenen ölçüde azaltamadığı görülmektedir. Dördüncü programın, kendisinden evvelki üç ayrı tebliğ ile uygulanan geri-alım programlarından herhangi bir farkının olmadığı görülmektedir. Bu programların hiçbiri; sistemde kalan balıkçıların etkinliğini ve gelirini arttıracak, sürdürülebilir balıkçılığ 1 katkı verecek herhangi bir ilave yönetim araciyla desteklenmemiştir. $\mathrm{Bu}$ haliyle programın balık stoklarının maksimum sürdürülebilir ürün seviyesinde sömürülmesine, aşırı kapasitenin engellenmesine ve balıç̧ılığa devam eden balıkçıların karlı bir balıkçılık yapabilmesine katkı vermesini beklemek iyimser bir yaklaşım olur. $\mathrm{Bu}$ nedenle, mevcut filonun ve av miktarı istatistiklerinin bir arada çok yönlü bir değerlendirilmesinin yapılması, gizli lisansların harekete geçip yeni gemiler olarak filoya dahil olup olmadiklarının belirlenmesi ve bundan sonraki geri-alım programlarının ilave önlemler ve düzenlemelerle desteklenmesi konularında harekete geçilmelidir. Zira bu türden lisanslar aktif filo içinde görünmez. Ortada balıkçı gemisi lisansı vardır ama balıkçı gemisinin kendisi yoktur. Ancak bu durum ilgili lisansın fiziksel olarak bir tekne ile buluşmasını ve filoya katılmasını engellemez. Dolayısıyla idareciler bir yandan, geri-alım programı ile gemi alıp filodan çıkarırken, diğer yandan lisansı olan bazı şahıslar gemi yaptırıp filoya dahil olabilir. $\mathrm{Bu}$ türden dinamiklerin izlenmesi ve gerekli önlemlerin alınması programın başarısı açısından kaçınılmazdır.

Türkiye balıkçılığının en önemli sorunları olarak karşımıza çıkan; aşırı avcılık, yasa dışı avcılık ve balıkçılık kapasitesinin aşırı artması gibi sorunlar, dünya ölçeğinde de birçok balıkçılık yönetiminin kronikleşmiş sorunları olarak kabul edilmektedir. Bununla birlikte, bunlar gelinen sonuçlardır ve sonuçtan ziyade balıkçılığı bu sonuca götüren nedenleri sorgulamak gerekir. Bartley (2019), dünyanın birçok bölgesindeki balıkçılık sistemlerinin dertte olmasını, etkili balıkçılık yönetimi programlarının geliştirilmesi ve uygulanmasına yönelik başarısız çabalar ve balıkçılık ekosisteminin insan bileşeninin yeterince dikkate alınmamış olmasıyla açıklamaktadır. $\mathrm{Bu}$ perspektiften bakıldığında, mevcut geri-alım programının, insan bileşenini ne ölçüde dikkate aldığını, sürdürülebilir balıkçılığa ve daha etkili bir balıkçılık yönetimine nasıl ve ne ölçüde katkı verdiğini sorgulamak gerekir. Balıkçılıkta geri-alım programlarının başarısının birçok faktöre bağlı olduğu göz ardı edilmiş gibi görünmektedir. Program sayesinde, balıkçılığın kronik problemlerinden herhangi birine çözüm getirilebildi mi? Tamamı 10-12 m arasında, küçük ölçekli 213 adet balıkçı gemisinin filodan çıkarılmasının avcılık kapasitesini belli ölçüde azalttığ kabul edilse dahi, bu gibi etkilerin çok kısa bir süre içinde yok olacağı hatta av kapasitesinin düşürülmesinde zorluklar yaşanacağı görülmüştür. Örneğin, milyarlarca Avroluk geri alım programlarının ardından, AB balıkçılık filosu kapasitesi tonaj ve motor gücü açısından ancak 1990'ların başından beri düşmeye başlamıştır. Balıkçı filosu, 2000 yılında 15 üyeli AB için 95200 gemiden oluşurken, 2015 yılında 28 üyeli AB için yaklaşık 84 400 gemiye düştü (Eurostat, 2016). Bu bağlamda, bu programların iyi planlanması ve etkilerinin iyi hesaplanması önemlidir. Bundan sonra yapılacak çalışmaların yukarıda bahsi geçen konulara açıklık getirmesi önemli bir boşluğu dolduracaktır. 20132018 yılları arasında gerçekleştirilen toplam beş gerialım programının balık stoklarına, sektörde kalan gemilerin karlılığına, tayfalara, av miktarına, filo yapısına çok yönlü etkilerini ortaya çıkarmaya yönelik çalışmalara ihtiyaç vardır. Eğer bu türden programlara devam edilecekse, bundan sonraki gerialım programlarının, söz konusu soruları ve sorunları dikkate alacak şekilde planlanması önerilmektedir.

\section{Kaynaklar}

Bartley, D. M. (2019). From Sustainability to Catastrophe to Recovery: The Need for Using an Ecosystem Approach for Responsible Fishery Management. Pages: 567-571 in C.C. Krueger, W.W. Taylor, and S. Youn, editors. From Catastrophe to Recovery: Stories of Fishery Management Success. American Fisheries Society, Bethesda, Maryland. 
Curtis, R., \& Squires, D. (2007). Fisheries Buybacks. Iowa: Blackwell Publishing. Ltd. ISBN: 13: 9780-8138-2546-5/2007, $267 \mathrm{p}$.

De Vaus, D. A. (1990). Surveys in Social Research. (2.bas $>$ m). London: Unwin Hyman.

Ekmekci, B. \& Ünal, V. (2019). Analysis of the second generation buy-back program for fishing vessels in Turkey. Ege Journal of Fisheries and Aquatic Sciences, 36(3), 229-243. DOI: 10.12714/egejfas.2019.36.3.04

Eurostat (2016). Data extracted in October 2016. https://ec.europa.eu/eurostat/statisticsexplained/index.php?title=Fishery_statistics_in_ detail\&oldid=311673.

Grafton, R.Q. (2008). Canadian Fisheries Governance: The good, the bad and the ugly. (Edt., N. Schneider) A breath of fresh air: the state of environmental policy in Canada. Fraser Institute, ISBN: 978-0-88975-241-2, Canada.

Groves, T., \& Squires. D. (2007). Lessons from Fisheries Buybacks. (Ed. R. Curtis and D. Squires) Fisheries Buybacks, 14-54. Iowa: Blackwell Publishing.

GTHB (2012). Resmi gazetenin 2012 tarihli ve 28328 sayısında yayımlanmış olan "Balıkçı Gemisini Avcılıktan Çıkaranlara Yapılacak Destekleme Tebliğii” (2012/51).

Göktay, S., Göncüoğlu-Bodur, H. \& Ünal, V. (2018). Analysis of the first buy-back program for fishing vessels in Turkey. Ege Journal of Fisheries and Aquatic Sciences, 35(4), 433-445. DOI:10.12714/egejfas.2018.35.4.09

Holland, D., Gudmundsson, E., \& Gates., J. (1999). Do Fishing Vessel Buyback Programs Work: A Survey of the Evidence. Marine Policy 23: 47-69

Newbold, P. (1995). Statistics for Business and Economics, Prentice Hall Inc., USA. Pages 1016.

Teh, L.S.L., Hotte, N. \& Sumaila, U.R. (2017). Having it all: can fisheries buybacks achieve capacity, economic, ecological, and social objectives? Maritime Studies, 16:1. DOI 10.1186/s40152-016-0055-Z

Squires, D. (2010). Fisheries buybacks: a review and guidelines. Fish and Fisheries. 11, 366-387. DOI: 10.1111/j.1467-2979.2010.00365.x

STECF (2015). The 2015 Annual Economic Report on the EU Fishing Fleet. Scientific, Technical, and Economic Committee for Fisheries (STECF 1507). Publications Office of the European Union, Luxembourg, 2015, EUR 27428 EN, ISBN 97892-79-50642-0 doi:10.2788/307845
STECF (2016). The 2016 Annual Economic Report on the EU Fishing Fleet. Scientific, Technical, and Economic Committee for Fisheries (STECF 1611). Publications Office of the European Union, Luxembourg, 2016, EUR 28375 EN, ISSN 18319424 doi: $10.2788 / 842673$

STECF (2017). The 2017 Annual Economic Report on the EU Fishing Fleet. Scientific, Technical, and Economic Committee for Fisheries (STECF 1712). Publications Office of the European Union, Luxembourg, 2017, EUR 28345 ISSN 19776578; 1831-9424 doi:10.2760/36154

STECF (2018). The 2018 Annual Economic Report on the EU Fishing Fleet. Scientific, Technical, and Economic Committee for Fisheries (STECF 1807). Publications Office of the European Union, Luxembourg, 2018, EUR 28359 ISSN 24670715/1831-9424 doi:10.2760/56158S

STECF (2019). The 2019 Annual Economic Report on the EU Fishing Fleet. Scientific, Technical, and Economic Committee for Fisheries (STECF 1906). Publications Office of the European Union, Luxembourg, 2019, EUR 28359 EN, ISBN 97892-76-09517-0, doi:10.2760/911768, JRC117567.

Ünal, V., Göncüoğlu, H. \& Göktay, S. (2015). Türkiye'de Balıkçı Gemisi Geri Satın Alma Programının Değerlendirilmesi. Ege Üni. Bilimsel Araşt. Projeleri, 013/SÜF/014, 46 s

Ünal, V \& Göncüoğlu-Bodur, H. (2020). Analysis of the third generation buy-back program for fishing vessels in Turkey. Ege Journal of Fisheries and Aquatic Sciences, 37(3), 1-1. Retrieved from http://www.egejfas.org/tr/issue/52051/648158 